\title{
Scanning Electron Microscope Configuration of Recycled Carbon Fiber Composites: Mini Review
}

\author{
Seyed Hossein Mamanpush ${ }^{1 *}$, Azadeh Tavousi Tabatabaei ${ }^{1,2}$ and Bahareh Tavousi Tabatabaei ${ }^{3}$ \\ ${ }^{1}$ Composite Materials and Engineering Center, USA \\ ${ }^{2}$ Department of chemistry, Iran \\ ${ }^{3}$ Department of Engineering, Iran
}

*Corresponding author: Seyed Hossein Mamanpush, Composite Materials and Engineering Center, USA

Submission: 㘹 October 25, 2018; Published: 海 November 06, 2018

\begin{abstract}
Carbon fiber composites (CFCs) were mechanically refined and classified the scanning electron microscope (SEM) configuration of untreated and heat-treated mechanically recycled carbon fiber epoxy and carbon fiber vinyl ester composite was examined by using scanning electron microscopy (SEM). SEM Results indicate that the main defects in the structure of recycled CFCs are broken fibers, fiber pull-out, fiber-matrix separation. Also Comparing SEM of untreated and heat-treated recycled CFC indicates that there is no significant difference between their micrographs.
\end{abstract}

Keywords: Carbon fiber composites; Recycling; Scanning electron microscope

\section{SEM Observation}

The CFC trimmings and off-cuts were mechanically refined through two methods: hammer milling with a $25.4 \mathrm{~mm}$ screen and shredding with $19 \mathrm{~mm}$ wide teeth. The hammer-milled material was then sieved to different fractions as retained in $19.05 \mathrm{~mm}$ (19.05), passed to $19.05 \mathrm{~mm}$ and retained $12.7 \mathrm{~mm}$ (12.7) passed $12.7 \mathrm{~mm}$ and retained $4.7 \mathrm{~mm}$ (4.7), and passed $4.7 \mathrm{~mm}(<4.7)$, respectively. The materials processed by the shredder were screened with a $12.7 \mathrm{~mm}$ screen and utilized as-is for the recycled composite process [1]. The SEM configurations of untreated and heat-treated recycled carbon fiber composites (rCFCs) are given in Figure 1. rCFCs were heat-treated at $360{ }^{\circ} \mathrm{C}$ for $10 \mathrm{~min}$ [2-4] based on the thermal properties of rCFCs. [5-8]. SEM configuration of CFCs shows different kinds of defects in the structure of composites including broken fibers, fiber pull-out, fiber-matrix separation. These defects maybe caused reaching of CFC to the end of life or can be created during recycling process [9-10]. Comparing SEM of untreated and heat treated $\mathrm{rCFC}$ indicates that there is no significant difference between their micrographs.
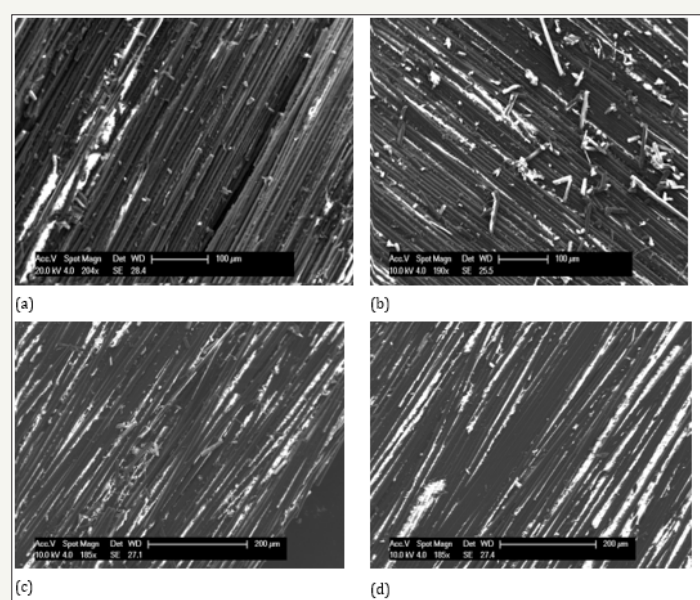

Figure 1: SEM configurations of $\mathrm{rCFC}$ under different conditions: (a) untreated Epoxy/CFC (b) heat-treated Epoxy/CFC (c) untreated $\mathrm{VE} / \mathrm{CFC}$ (d) heat-treated $\mathrm{VE} / \mathrm{CFC}$. 


\section{References}

1. Hui Li, Karl Englund (2016) Recycling of carbon fiber-reinforced thermoplastic composite wastes from the aerospace industry. Journal of Composite Materials 51(9): 1265-1273.

2. Mamanpush H, Golestanian $H$ (2014) Investigating the effects of carbon nanotube orientation on the macroscopic stiffness of nanocomposites. Int J Curr Life Sci 4(4): 1168-1174.

3. Mamanpush H, Golestanian H (2014) Evaluation of effective material properties of randomly distributed carbon nanotube composites considering interface effect. Indian J Sci Res 2(1):132-142.

4. Thostenson ET, Karandikar PG, Chou TW (2005) Fabrication a characterization of reaction bonded silicon carbide/carbon nanotube composites. J Phys D Appl Phys 38(21): 3962-3965.

5. Song YS, Youn JR (2006) Modeling of effective elastic properties fo polymer-based carbon nanotube composites. Polymer 47(5): 1741-1748.
6. Mamanpush H, Golestanian H (2014) Effects of carbon nanotube dispersion on the mechanical properties of nanocomposites considering interface effect. International Journal of Current Research 4(8): 4366- 4373.

7. Seyed Hossein Mamanpush, Hui Li, Karl Englund, Azadeh Tavousi Tabatabaei (2018) Recycled wind turbine blades as a feedstock for second generation composites. Waste Management 76: 708-714.

8. Seyed Hossein Mamanpush, Azadeh Tavousi Tabatabaei, Hui Li, Karl Englund (2018) Data on the mechanical properties of recycled wind turbine blade composites. Data in Brief 19: 230-235.

9. Seyed Hossein Mamanpush, Hui Li, Karl Englund, Azadeh Tavousi Tabatabaei (2018) Dataset demonstrating physical properties of recycled wind turbine blade composites. Data in Brief 20: 658-661.

10. Seyed HM, Azadeh TT (2018) Innovative method in recycling wind turbine blades: mini review. Evolutions Mech Eng 1(1). 1-2.
Creative Commons Attribution 4.0 International License

For possible submissions Click Here

\section{Submit Article}

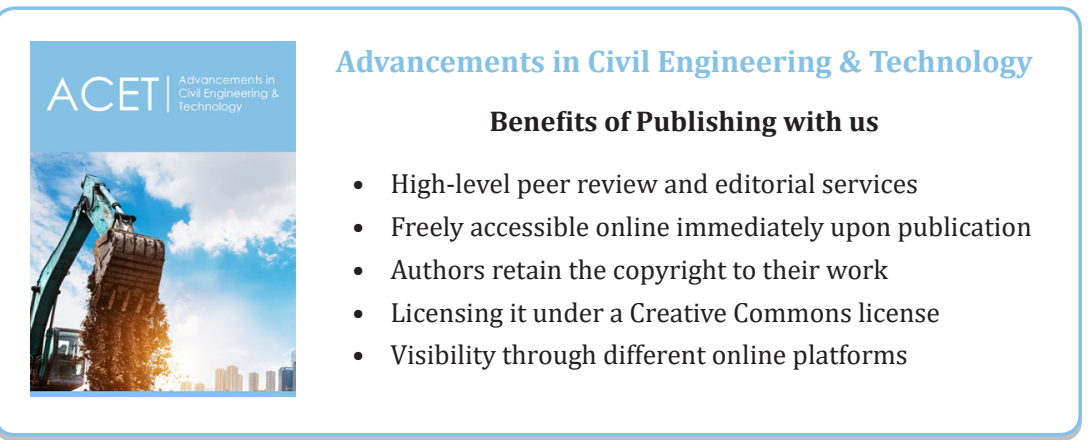

